Paidéia, 2002, 12(23), 149-162

\title{
EVOLUÇÃO INICIAL DOS ESTUDOS DA INTELIGÊNCIA DO IDOSO: MITOS E FATOS ${ }^{1}$
}

\author{
Reinier Johannes Antonius Rozestraten ${ }^{2}$ \\ Universidade Católica Dom Bosco
}

\begin{abstract}
RESUMO: Apresentamos nesse artigo o início e o primeiro desenvolvimento dos estudos sobre a inteligência do idoso dentro do quadro das fases da psicogênese do comportamento : tomada de informação, processamento de informação, tomada de decisão, comportamento-resposta efeedback. Através dessa evolução que teve seu início no fim da I Guerra Mundial vêem-se surgir três mitos que aos poucos foram refutados: a) o mito que a inteligência é uma capacidade única em vez de um conjunto de diversas capacidades que se combinam de múltiplas formas; b) o mito que a inteligência como totalidade única se deteriora durante a velhice, enquanto se verificou posteriormente que apenas algumas capacidades agrupadas como inteligência fluida são afetadas enquanto outras caracterizadas como inteligência cristalizada ficam constantes ou até melhoram; e c) a idade avançada é o único fator que influencia o desenvolvimento ou deterioração das capacidades intelectuais. Em relação ao último mito Lehr afirma que há pelo menos mais nove fatores influentes: declínio de fator $\mathrm{G}$, rapidez, aptidão inata, nível educacional, treinamento, ambiente estimulante, saúde, sucesso na vida e motivação.
\end{abstract}

Palavras-Chave: inteligência geral, inteligência fluida, inteligência cristalizada, inteligências múltiplas, habilidades

\section{INITIAL EVOLUTION OF ELDERLY INTELLIGENCE STUDIES: MYTHS AND REALITY}

\begin{abstract}
This paper presents the beginning and the first development of studies about the intelligence of the aged within the frame of the five phases of behavior psychogenesis: Information intake, information processing, decision making, response-behavior and feedback. In the course of this evolution that starts at the end of World War I, three myths emerged that successively were refuted: a) the myth that intelligence is a unique massive capacity instead of a joint of several capacities which may combine in multiple forms; b) the myth that this unique intelligence in its totality deteriorates during old age, but later was verified that only some capacities named "fluid intelligence" are affected meanwhile others characterized as "crystallized intelligence" are constant or even improved; e c) the old age factor is the unique factor that influences the development or deterioration of intellectual capacities. To this last myth Lehr asserts that there are at least more nine influencing factors: Decline of the $G$ factor , speed, innate aptitude, educational level, training, stimulating environment, health, successful life and motivation.
\end{abstract}

Key-words: Factor "g", Fluid intelligence, Crystallized intelligence, Multiples intelligences, Skills

Julgamos importante tecer algumas considerações gerais sobre o estudo do idoso antes de entrar no próprio assunto.

Em primeiro lugar devemos ressaltar o cará-

\footnotetext{
${ }^{1}$ Artigo recebido para publicação em fevereiro de 2002; aceito em abril de 2002

2 Endereço para correspondência: Reinier Johannes Antonius Rozestraten, Rua Amazonas, 1186, Apto. 102, Vila Rosa, Cep. 79022130, Campo Grande, MS, E-mail reinierr@terra.com.br
}

ter interdisciplinar dos estudos sobre o idoso. A razão é simples: o idoso é um ser humano e como tal complexo, um ser multifacetado que pode ser considerado sob diversos aspectos: anatômico, fisisiológico, sociologico, psicológico, pedagógico, econômico, ergonômico, cronológico, ético, estético, lúdico etc. Cada um desses aspectos pode ser estudado por uma ou mais ciências. Todas essas ciências devem 


\section{Reinier Johannes Antonius Rozestraten}

ser ouvidas se quisermos ter uma imagem mais global do idoso, pois cada uma tem algo importante a dizer sobre sua maneira de ver, de pensar e de comportar-se.

Em segundo lugar, temos que assinalar uma grande diferença entre o tipo de perfil das características bio-psico-sociais que pode ser construído para uma determinada idade na infância e o que se pode construir de uma determinada idade na velhice. Temos um conceito claro daquilo que um menino normal e sadio de sete anos é capaz de fazer, quais suas capacidades físicas e psíquicas, mas não temos um perfil claro de um idoso de 70 anos. Ele pode ser um famoso maestro, um grande pintor, um político honesto ou não, um ilustre pesquisador, mas também pode ser um esclerosado, um desmemoriado, que nem reconhece mais seus filhos e que deve ser tratado como um bebê. Ele pode também estar em algum lugar na extensa gama entre esses dois extremos. As diversas pesquisas feitas em idosos mostram freqüentemente que há grandes diferenças individuais entre pessoas de uma mesma faixa etária, e maiores do que entre pessoas de faixas etárias anteriores.

Em terceiro lugar, não há na terceira idade uma sequiência de fases de desenvolvimento, como há na infância e que foi brilhantemente pesquisada e definida por Jean Piaget. Não há um programa inato epistemológico que aos poucos vai se desenrolando e em que cada etapa depende da etapa anterior. No idoso não há uma seqüência evolutiva de etapas na decadência dos diversos órgãos. Enquanto um idoso começa a sofrer do aparelho digestivo, o outro começa com dificuldade na circulação. O que é certo é que o organismo vai se desgastando igual a uma máquina, com algumas partes se deteriorando mais e outras menos. Os estudos de Bromley (1969) mostraram que de 20 aos 80 anos a velocidade de condução da fibra nervosa e o peso do cérebro diminuem em $15 \%$, o rendimento cardíaco e o peso do fígado diminuem em $35 \%$, a capacidade vital e o tempo de reação à luz e ao som por volta de $50 \%$, e a freqüência de relações sexuais no homem em $75 \%$.

Em quarto lugar, há uma diferença na perspectiva futura. Em geral o idoso não estabelece um grande alvo de realização, mesmo existindo boa quantidade de idosos que gostam de continuar trabalhan- do, de se sentir úteis e de partilhar sua experiência com os mais jovens. Muitos vivem simplesmente $o$ cotidiano, conversam, jogam e querem se manter informados, mas sem grande atividade.

Em quinto lugar, o idoso tem frequientemente uma consciência de estar mais perto da morte. Para uns isso é um motivo de tranqüilidade e de paz, para outros um motivo de pavor. A fé de encontrar um outro mundo mais justo e com mais amor depois da morte ou a incerteza de um pulo no escuro. Seja como for, o idoso é confrontado repetidamente com a morte de familiares, de colegas e de amigos de sua geração sofrendo de doenças e debilitações.

Por fim, podemos aceitar que a velhice é principalmente um produto de processos bioquímicos ao nível molecular. Esta velhice molecular surge principalmente por causa de radicais livres que são fragmentos de moléculas com alta reatividade química que provêm das reações químicas do próprio organismo, dos alimentos ou do ar inspirado. As ligações com essas radicais endurecem as substâncias, tornando-as quebradiças. Isto acontece com borracha velha e acontece também com a nossa pele; as nossas artérias e articulações endurecem, enrijecem e se tornam quebradiças (Gaiarsa, 1986). Os discos intervertebrais se encolhem, a substância gelatinosa nos ossos desaparece tornando os ossos similares a cálcio puro, provocando fraturas sérias por unia simples queda, fora os estragos que a osteoporose possa causar.

As fases da construção do comportamento

Praticamente todo comportamento é uma resposta ao ambiente, seja o ambiente real ou memorizado. Podemos distinguir essencialmente três tipos de ambientes: o Ambiente Físico (constituído do todo o material físico ẹm torno de nós, casa, escola, edifícios, livros, alimentos, veículos etc), o Ambiente Social (formado por familiares, amigos e colegas e por qualquer cidadão que encontramos e até por animais) e o Ambiente Normativo (o conjunto de leis e de normas que devemos seguir nas diversas situações, as regras da sociedade que fazem funcionar a sociedade de tal modo que os direitos de todos são respeitados e cada um pode cumprir seus deveres de trabalho e de justiça). Destes ambientes provêm os 
estímulos que são os primeiros fatores que provocam nosso comportamento.

A primeira fase para entrar em contato com estes estímulos é a Tomada de Informação. Nossos órgãos de sentido: olhos, ouvidos, pele, olfato, gosto e terminações cinestésicas nos informam sobre o que se passa nos ambientes, criando uma representação deles em nós de forma que depois poderemos reagir adequadamente aos estímulos do ambiente ou da situação. Sem estas informações perceptivas nossa inteligência não poderá funcionar.

$\mathrm{Na}$ segunda fase damos sentido ao representado, é a fase do Processamento da Informação, com a ajuda da memória reconhecemos as coisas percebidas e compreendemos o que está acontecendo. Compreendemos que estamos numa situação de perigo, da qual temos que sair rapidamente, ou estamos enfrentando um problema profissional que temos que resolver. É nesta fase que mobilizamos todos os conhecimentos sobre a representação. Nossa inteligência trabalha sobre aquilo que nossos órgãos de sentido nos apresentam. Sem esta representação perceptiva nossa inteligência fica cega e sem atividade; ela tem que ter algo sobre o que pensar. Pensamos sobre os comportamentos mais adequados nessa situação, pensamos sobre nossas possibilidades, julgamos o que é melhor fazer, o que é mais justo, mais seguro ou moralmente melhor. Desta forma fazemos também uma previsão. Quais são os resultados quando faremos isto ou aquilo, o que provavelmente vai acontecer?

Entramos assim na fase seguinte que é a Tomada de Decisão. Decidimo: eu vou fazer isto ou aquilo. Posso também decidir fazer nada ou simplesmente continuar fazendo o que estava fazendo. Posso decidir respeitar a lei ou não respeitar a lei, ser um cidadão honesto ou um cidadão corrupto. A decisão é a porta através da qual a reflexão da inteligência passa para a ação, torna-se um comportamento.

A quarta fase é então a fase da Resposta ou do Comportamento. Colocamos em prática aquilo que decidimos. O comportamento resultante naturalmente depende de treino, quanto mais bem treinado, melhor sai o comportamento. Como numa equipe de futebol: quanto maior o treino melhor será o jogo. $O$ exercício e o treino formam a base de comportamen- tos mais adequados; entra aqui a memória motora e a capacidade de adaptar-se a uma nova situação. Chegamos nessa fase à verdadeira meta da construção: o comportamento acabado. No entanto falta ainda alguma coisa. Observando nosso comportamento podemos perguntar: é isto o que queremos fazer, os resultados desse comportamento são aqueles que desejamos ou poderiam ser melhores?

Entramos assim numa última fase: o Feedback, a Retroalimentação, ou melhor, $o$ Controle sobre o Comportamento. Nesta fase observamos o comportamento e seus resultados e o comparamos com aquilo que imaginamos quando estávamos no Processamento de Informação. Aquilo que foi feito está de acordo com aquilo que foi planejado? Se não estiver, temos que começar todas as fases de novo e construir um comportamento mais adaptado e mais adequado à situação.

Vejamos um exemplo concreto: dirigir um carro. Vamos supor que o motor já está funcionando, você quer sair do lugar onde está estacionado. Que fazer? Você ouve o motor, está normal. Você, pelos espelhos retrovisores, vê se vem carro de trás, se o caminho está livre para sair: Tomada de Informação. Você interpreta o que está vendo: o caminho está livre; para sair vou ter que virar o volante à esquerda; vou ter que desviar do carro que está estacionado um pouco a minha frente ou vou ter que pisar lentamente no acelerador para não dar uma arrancada brusca e depois desta vou ter que mudar para a segunda marcha. Tomo a decisão: vou sair agora, está tudo OK. Já estou virando o volante e apertando o acelerador: o comportamento. Vejo que ao endireitar a direção do carro puxei o volante um pouco demais para a direita: Feedback e Tomada de Informação. Assim vou bater nos carros que estão estacionados: Processamento de Informação. Decido virar o volante um pouco para a esquerda: Tomada de Decisão. Virou o volante: Comportamento; agora a direção do carro está certo: Feedback.

O ciclo das fases continua rodando: Tomada de Informação, Processamento de Informação, Tomada de Decisão, Comportamento, Feedback e de novo Tomada de Informação, etc. Sempre de novo: observar a situação, interpretar e compreendê-la, decidir o que fazer, agir e controlar os efeitos da ação. Cada fase depende da fase anterior. Vários dados 


\section{Reinier Johannes Antonius Rozestraten}

podem ser percebidos e processados ao mesmo tempo. Enquanto vejo o farol do semáforo, vejo também o pedestre que quer atravessar, o carro que vem em sentido contrário e o cachorro que já está atravessando, enquanto um motociclista está ultrapassando meu carro (Rozestraten, 1988a). O ciclo destas etapas não apenas se aplica ao trânsito mas a qualquer comportamento: fazer um bolo, limpar a casa, trabalhar no computador, jogar uma partida de futebol ou de tênis. Sempre as cinco fases estão aí. Muito depende da Tomada de Informação, se esta for mal feita o resto vai sair errado. A inteligência trabalha sobre os dados sensoriais e esses devem ser corretos. Muitas vezes minhas emoções podem intervir (Coleman,1995) e me fazer perceber mais ou diferente daquilo que na realidade existe.

Através de muitas repetições os comportamentos podem ficar automatizados, não se precisa mais pensar, nem tomar uma decisão. Quer ir mais rápido? Tem que mudar a marcha, você faz isso sem refletir, sem tomar conscientemente uma decisão, vai direto da Tomada de Informação para o Comportamento. Semáforo vermelho à pé no freio, mesmo quando você está conversando com seu passageiro.

No entanto, se todo o trabalho consiste de automatismos isto pode levar à loucura, como mostrou magnificamente o filme Modern Times de Charlie Chaplin e foi amplamente discutido por Dejours (1987).

\section{Como a velhice afeta as fases da construção do comportamento}

\section{A tomada de informação ou a construção da re- presentação}

Uma vez que a Tomada de Informação influencia todas as outras fases, fica claro que uma diminuição nas capacidades sensoriais pode deteriorar os desempenhos da inteligência e do comportamento, 0 que não quer dizer que a inteligência em si deteriorou ou que o idoso não sabe mais se comportar adequadamente. Vejamos as principais entradas sensoriais:

- Na Visão podemos distinguir vários aspectos:

a) A Acuidade Visual, ou seja, a capacidade de ver pequenos detalhes. Esta é pouco desenvolvida na criança e aumenta até a idade do jovem adulto. Dos 20 aos 30 anos há um pequeno declínio que se intensifica depois dos 50. Vários fatores colaboram para esta deterioração que geralmente termina em presbiopsia ou "vista cansada" do idoso, vendo melhor de longe do que de perto, por falta da acomodação da lente que perdeu sua elasticidade. Juntamente há uma redução no tamanho da pupila até $25 \%$ que causa uma diminuição da quantidade de luz que cai no olho; muitas vezes o idoso precisa de mais luz para ver bem.

b) A Visão noturna diminui, de modo que o limiar de detecção de uma luz fraca aumenta consideravelmente com a idade. Robertson e Yudini (1944) atribuíram esta diminuição à redução da pupila; Birren e cols. (1983) porém acham que este fator não afeta tanto o limiar. Administração de vitamina A não resulta em melhora. Verificou-se ainda que para o idoso a duração do estímulo luminoso deve ser maior para poder ser bem visto.

c) A Sensibilidade ao Ofuscamento aumenta: o olho exposto a uma luz forte à noite demora mais para voltar a ver com uma acuidade normal. Conseqüentemente, aconselha-se ao idoso para não dirigir à noite (Rozestraten,1997).

d) A Visão Periférica reduz com a idade. Verificou-se uma redução no campo dos bastonetes do olho adaptado ao escuro de $20^{\circ}$, pois, nas pessoas de 10 a 30 anos, é de $60^{\circ}$ a partir da linha de visão e, nas de 60 a 70 anos, é de $40^{\circ}$. A redução do campo de visão faz com que, muitas vezes, as coisas apareçam de repente ao idoso, inesperadamente. Isto pode causar pavor e acidentes de trânsito.

e) A Visão Cromática ou a Discriminação de cores não sofre praticamente nenhuma diminuição dos 20 aos 64 anos. Porém, além dos 64 anos se constata, às vezes, uma queda brusca nesta capacidade. Esta queda, no entanto, depende também do treino e da experiência. Uma pessoa que sempre lida com cores terá uma regressão muito menor que outra que não lida com elas.

f) A Percepção Analítico-Sintética Verville e Cameron (1946) verificaram em pessoas entre 36 e 56 anos que os mais velhos exigiam 
tempo para perceber o que faltava em figuras mais complexas. Shinar e cols. (1978) constatou o mesmo padrão de resultados num experimento envolvendo a capacidade visual de reserva. Usou uma amostra de seis jovens, independentes do campo, de 20 a 25 anos e nove idosos, dependentes do campo de, 63 a 73 anos. Os independentes do campo visual descobrem com facilidade uma figura simples escondida numa figura complexa $e$, os dependentes do campo têm dificuldade de descobrir essa figura simples e demoram mais ou não conseguem descobri-la. A média do tempo de realização do teste de figuras simples embutidas em figuras complexas (Embedded Figures Test - EFT de Witkin) nos idosos foi sete vezes maior do que nos jovens. Para medir a capacidade visual de reserva, as pessoas deveriam, durante a condução de um veículo manter, os olhos fechados durante o maior tempo possível, sem prejudicar a segurança e a condução do veículo numa pista de corrida. Desta forma, evidenciou-se que quanto mais dependente a pessoa é, mais tempo precisa manter os olhos abertos. Os periodos contínuos de olhos abertos ou fechados foram mais curtos nos jovens. Isto sugeriu que os dois grupos funcionam conforme esquemas temporais diferentes: os idosos abrem e fecham os olhos menos freqüentemente que os jovens, mas os mantêm abertos por mais tempo.

$\mathrm{Na}$ Audição temos primeiro uma perda no sentido de uma diminuição da amplitude de freqüências ouvidas: esta perda aumenta com a idade e é maior nos homens do que nas mulheres. Ela é mais grave nas frequüências acima de 1.024 $\mathrm{Hz}$. Bunch (1931) traçou curvas audiométricas médias de 32 a $16.384 \mathrm{~Hz}$, em décadas de 20 a 60 anos, e constatou que a perda de audição com a idade era pouca até aos $512 \mathrm{~Hz}$. Pessoas expostas a sons e ruídos fortes sofreram maior redução. Por falta da audição das frequiências mais altas (sons mais agudos), esses sons para os idosos ficam mais pobres, menos cheios e menos diferenciados. Para muitos idosos os sons agudos, por exemplo gritos de crianças, são extremamente irritantes.
A deficiência auditiva para sons mais agudos em pessoas acima de 50 anos é de significância psicológica, pois a percepção de frequiências mais altas desempenha um papel importante na compreensão de conversa quando várias pessoas estão falando ao mesmo tempo (cocktail party). A fim de detectar esta deficiência basta falar mais baixo e mais depressa para verificar a não compreensão.

No adulto normal há um nível ótimo e um nível máximo de audição, este último é o limiar. Por exemplo, a menor intensidade de som que permite a percepção de palavras. A distância entre ótimo e máximo (o mínimo de som) no adulto é relativamente grande, mas no idoso quase se sobrepõem.

Em geral há nos idosos uma modificação nos limiares perceptuais absolutos e diferenciais: ambos pioram. A sensibilidade à luz mínima diminui e a sensibilidade ao ofuscamento aumenta. Precisa-se de mais luz para ver bem, a sensibilidade ao frio e aos sons aumenta e, as diversas diferenças entre as cores e os sons, não são mais tão nítidas. A discriminação entre os gostos e os cheiros diminui, confundem-se os rostos das pessoas, o tempo de reação aumenta e tudo isto influencia necessariamente o desempenho intelectual e comportamental.

Quanto à Kinestesia ou ao Sentido muscular, as informações são menos abundantes e precisas. Porém, não há dúvida que também aqui há perdas. O idoso tem muitas vezes de esforçarse mais para realizar pequenos movimentos muito precisos. Não falamos aqui da doença de Parkinson, mas de simples perda de sensibilidade fina. No entanto é certo que um treino diário como por exemplo de senhoras que fazem diariamente bordado ou tricô pode ajudar bastante para manter por muito tempo este sentido em bom estado.

Para manter o sentido Estato-kinestésico de equilíbrio e de deslocamento em bom funcionamento, exercícios como ginástica, yoga e natação podem ajudar muito. Sem isto o idoso pode ficar ameaçado de perder o equilíbrio simplesmente quando muda mais ou menos bruscamente de direção; por isso quedas podem-se tornar mais 


\section{Reinier Johannes Antonius Rozestraten}

freqüentes. Idosos que continuam usando bem seu organismo, exercitando-o com boa regularidade, podem manter por mais tempo seu funcionamento perfeito, apesar do envelhecimento. A melhor maneira de envelhecer mais rapidamente é sentar-se ou deitar-se, sem fazer nada, ou somente olhando a TV.

A Atenção ou a percepção dirigida está dentro da Tomada de Informação e constitui até seus primeiros momentos. Ela pode ser difusa (vigilância), concentrada sobre um determinado ponto ou distribuída sobre vários objetos (Wright, 1981). Todos esses tipos de atenção diminuem com a idade, seja em intensidade, seja durante o tempo durante o qual podem ser mantidas. $O$ controle de um quadro de vários instrumentos de medida não é bem um trabalho para um operário idoso, apesar de exigir pouco esforço muscular.

\section{o Processamento de Informações - Visão Geral das Operações da Inteligência}

Esta fase engloba a operação da construção do conhecimento que repousa sobre a memória e de seu uso na aplicação dele sobre a situação percebida, levando a uma compreensão dela. Vários caminhos podem se oferecer para a solução de uma situação problemática, cada um pode ser considerado com a previsão de seus resultados. $O$ conhecimento depende da aprendizagem, do treinamento e da experiência. Todas são operações da inteligência que têm acesso ao que foi memorizado, que são capazes de aplicar normas abstratas a situações concretas, que podem refletir, tirar conclusões, descobrir regularidades e leis, fazer julgamentos sobre valores éticos e estáticos, sobre valores filos 6 ficos, epistemológicos ou religiosos. A inteligência é capaz de encontrar pela reflexão a solução de um problema, testando depois, através do comportamento na situação real, a adequação desta solução. Ela pode formular várias hipóteses prevendo as situações futuras possíveis e já preparar os tipos de comportamentos que serão adequados a estas situações. Com ela a humanidade construiu as mais variadas filosofias, construiu sua cultura, suas cidades, suas múltiplas artes, suas ciências e as infinitas aplicações delas, suas religiões e suas crenças. Tam- bém levou a conquistas, a guerras, a matanças e a invenção de mais sofisticadas máquinas mortíferas, levou a extirpação de raças e a genocídios.

A inteligência é à base de tudo em que o "mundo do homem" se diferencia do "mundo do animal". Muitas coisas boas e algumas bem ruins, até a destruição de seu próprio ambiente ecológico. Nenhuma espécie conseguiu tão bem construir seu ambiente próprio destruindo $o$ ambiente natural.

Como se vê por esta breve descrição a inteligência não é algo tão simples de definir. Na realidade é um nome genérico para uma quantidade de capacidades de operações. Aos poucos os psicólogos estão se afastando mais e mais do conceito de "Inteligência Geral" ou "fator G" introduzido por Spearman (1904). Com isto cai um primeiro mito, aquele que considera a inteligência como uma grande potencialidade básica com uma função inteligente geral, mesmo acreditando que há diversas capacidades intelectuais específicas, indicadas como fatores numéricos, verbais, especiais, etc da inteligência.

\section{Os Testes de Inteligência}

Bem no começo do século passado Alfred Binet desenvolveu, a pedido do ministro de educação, uma escala de inteligência para homogeneizar as classes do ensino fundamental. Esta escala era construída de várias pequenas baterias de testes de operações intelectuais próprias para cada idade e era de aplicação individual. Este teste foi mais desenvolvido na universidade de Stanford e atualmente é conhecido com o Teste de Terman-Merrill, permitindo determinar o Q.I. de criança até adulto.

Porém, quando os Estados Unidos entraram na primeira guerra mundial, tinham que se selecionar entre os recrutas as pessoas adequadas para um treinamento de oficiais. Por falta de unificação na avaliação do sistema escolar, desenvolveram-se em 1917 testes grupais para a medição da inteligência de adultos. A American Psychological Association formou uma comissão dos mais eminentes psicólogos neste campo. Esta comissão formou uma bateria de testes que foi pesquisada quanto a sua validade e fidedignidade. O resultado foi satisfatório e o Ministério de 


\section{Evolução Inicial dos Estudos da Inteligência do Idoso 155}

Guerra estendeu os testes psicológicos para todo o exército. De setembro de 1917 a janeiro de 1919 foram testados 1.726 .966 militares entre os quais 42.000 oficiais.

Assim se construíram os testes Army Alpha para os alfabetizados e Army Beta para os analfabetos. Seus resultados em homens de 18 a 60 anos foram publicados por Yerkes em 1921. Mostrou-se que, em termos de Desvio Padrão, o declínio do envelhecimento já era visível a partir de 30 anos. Yerkes, no entanto, avisou que este resultado não deveria ser visto como uma diminuição da inteligência em função da idade: mostrou que havia outros fatores que poderiam ter influenciado nos resultados.

A Aplicação dos Testes de Inteligência em Idosos

Foster e Taylor (1920) foram os primeiros a realizar um estudo mais específico sobre a inteligência do idoso. Aplicaram o teste Arma Alpha a grupos de pacientes num hospital de Boston. Compararam os pacientes de 59 a 84 anos com um grupo de pacientes de 20 a 30 anos e com escolares de 10 a 19 anos. Nos resultados finais, os mais velhos estavam com os resultados mais baixos. Porém, olhando os subtestes, viu-se que os idosos tiveram resultados mais baixos nos testes de associações verbais (com o fator tempo delimitado), cópia de modelos, composição de frases a partir de três palavras e frases para completar a partir de fragmentos de frases. Porém, tiveram resultados superiores no vocabulário, no teste de julgamento e no teste de compreensão.

Jones e Conrad publicaram em 1933 um outro estudo feito no meio rural baixo com 1191 pessoas entre 10 e 60 anos usando o teste Army Alpha. Os resultados não mostraram diferenças quanto ao vocabulário e quanto à compreensão de informações, achar analogias, ver conexões e continuar séries numéricas. Jones, no entanto, alertou contra generalizações destas evidências, pois viu que as diferenças dentro do mesmo grupo etário eram maiores do que entre os diversos grupos etários.

O primeiro grande Instituto de Psicologia para o estudo de mudanças psicológicas ligadas à idade foi fundado em 1928 por Miles, na Universidade de Stanford. Ele usou uma bateria de tes- tes perceptivos, testes de inteligência (Otis) e testes psicomotores. O Ql médio diminuiu com a idade: 20 anos: 114, 50 anos: 102. Miles (1932) fez uma divisão em sete classes de qualidade dos resultados intelectuais nos diversos grupos de idade. Encontrou que pessoas com QI mais alto fizeram uma compensação da perda com idade usando a experiência, a segurança e a técnica de aprendizagem, enquanto os com QI mais baixo não conseguiram esta compensação.

Perto do fim da II Guerra Mundial David Wechsler (1955) realizou uma das mais importantes pesquisas com sua escala WechslerBellevue de inteligência. Esta escala tem a vantagem de apresentar uma parte de testes verbais (1. Conhecimento geral, 2. Compreensão geral, 3. Inteligência aritmética, 4 . Memória numérica, 5. semelhanças e 6. vocabulário) e outra de testes não verbais ou de execução (7. completação de figuras, 8. organização de figuras, histórias em quadrinhos, 9 formação de figuras, quebra cabeça, 10. mosaico - Kohs, 11. símbolos numéricos). Outra vantagem é que esta escala permite comparação fácil entre resultados de várias amostras.

Globalmente os resultados confirmaram a curva típica do teste Army Alpha quanto às mudanças de inteligência com a idade. $O$ ponto mais alto se alcança entre 30 e 40 anos e depois há uma diminuição. Porém, constataram-se diferenças entre os resultados dos testes verbais e nãoverbais. A parte verbal acusava um declínio somente depois de 70 anos, enquanto na parte não verbal o declínio era maior e começava mais cedo.

Análises posteriores, no entanto, mostraram que se podem distinguir dois tipos de resultados e que ambos abrangem tanto testes verbais como testes de execução:

a) Um grupo de testes independentes da idade (constantes, permanentes): os verbais: conhecimento geral, compreensão geral, vocabulário e habilidade de linguagem, e os de execução: formação de figuras e completação de figuras. Em outras palavras, mais ou menos constantes são: o conhecimento geral, o julgamento prático, a capacidade de resolver problemas comuns, a habilidade de linguagem, a atenção e concentração,a fantasia construtiva 
156 Reinier Johannes Antonius Rozestraten

e a capacidade de diferenciar o essencial do secundário.

b) Um grupo de testes dependentes da idade (variáveis com a idade, declináveis, não permanentes): os verbais: memória numérica, inteligência aritmética e semelhanças e símbolos numéricos, e os de execução: ordenação de figuras, teste mosaico. Em outras palavras pioram com a idade: a memória, a capacidade perceptiva, a flexibilidade e a rapidez de mudar o ponto de vista, o pensamento lógico abstrato, a rapidez psicomotora e a capacidade de combinar (Birren \& Morrison,1966).

\section{- O Mito do Modelo de Declínio}

Apesar dessas últimas evidências, as curvas gerais de declínio e de uma regressão geral da inteligência de Miles, Jones-Conrad e Wechsler, tornaram se mais populares e colaboraram para a difusão do chamado "Modelo de Declínio" (déficit model). Este modelo é um segundo mito a ser destruído: a capacidade intelectual geral mostraria um declínio com o avançar da idade já a partir dos 20 anos. Para reforçar este mito Lowe \& McCormick (1955) formulou seu postulado de Orientação Biológica sobre a qual se baseia sua hipótese de Adolescência Máxima.

Outro trabalho que muito contribuiu para a crença neste mito foi o de Lehman nos anos sessenta $(1964,1965,1966)$. Ele pesquisou a questão: "Qual a idade em que as pessoas de diversas profissões e ciências realizaram seu melhor trabalho?" Suas conclusões eram: os melhores trabalhos qualitativos caem entre 25 e 35 anos. Os recordes esportivos caem mais cedo entre $17 \mathrm{e}$ 21 anos. Nas ciências naturais entre 26 e 30 anos , na medicina por volta de 30 anos e, em política e liderança religiosa, no decênio de 60 .

Como explicação para a diminuição do desempenho Lehman apresenta:

1. dados físicos (a base é uma curva biológica);

2. influências sociais perturbadoras;

a) falta de impulso para a realização (situação financeira fixa)

b) falta de impulso para fazer carreira (promoção impossível)

c) mudança de escala de valores (aproveitar a velhice)

d) erros de memória se tornam mais freqüentes

e) atitude inflexível

f) dificuldade de se adaptar a novas situações.

Este trabalho foi muito citado porém infelizmente pouco se citam as críticas que vieram de vários lados. Uma das melhores é a de Dennis (1966):

1. O critério de frequiência de citação, usado por Lehman, para julgar a qualidade da obra é questionável:

a) obras que lançam idéias que chamam atenção são freqüentemente mais cotadas que obras melhores de anos depois;

b) muitas obras somente são avaliadas com o seu devido valor muito tempo depois de serem realizadas;

c) há preconceitos contra trabalhos de cientistas idosos, porque muitas vezes suas obras são mais difíceis e exigem mais conhecimentos.

2. Objeções metodológicas:

a) Lehman não levou em conta os que morreram cedo e não podiam publicar em idade avançada.

b) Cada ano aparecem mais publicações e, assim faz-se preciso classificação mais refinada da mesmas.

Outros fatores que influenciam a Inteligência na Velhice:

Existem, conforme Lehr (1980), pelo menos nove aspectos nos quais se pode criticar o Modelo de Declínio, que considera somente o fator "idade" como determinante da evolução da inteligência.

a) A Decadência do Fator G. Embora já tenhamos mencionado a recente recusa total, ou parcial, da "inteligência geral" ou o "Fator G" de Spearman, voltamos aqui ao assunto. $O$ que se quer colocar em lugar?

Riegel (1960) põe que a inteligência deve ser considerada como "uma unidade funcional de funções primárias relativamente independentes, que colaboram na solução de diversos problemas, sempre numa nova composição". Quanto às mudanças ligadas à ida- 
de ele diz que "características intelectuais parecem estar sujeitas a deslocamento irregular e a reorganização durante a vida". Em outras palavras, "diversas aptidões alcançam seu ponto alto em diversos momentos e têm um padrão diferente de desenvolvimento".

Nos anos 60, Horn e Cattell (1966) introduziram a distinção entre "inteligência fluida" e "inteligência cristalizada". A primeira é a capacidade de mudar facilmente de ponto de vista, é a mobilidade, o saber adaptar-se a novas situações, a habilidade de fazer novas combinações, etc. Conforme argumentam esses autores a "inteligência fluida" diminui com os anos, mas a "inteligência cristalizada" que engloba o conhecimento geral, o vocabulário e o conceito de linguagem, pode até crescer e desenvolver-se mais com os anos.

Helander (1967) pesquisou na Suécia uma amostra de 400 operários, pelo método de análise fatorial, sobre mudanças de desempenho em idade mais avançada. Chegou a cinco fatores de inteligência dos quais somente um correlacionava-se positivamente com a idade, um outro negativamente e três não mostraram correlação nenhuma. $\mathrm{O}$ fator que aumentava era o uso da linguagem (inteligência cristalizada); diminuíram com a idade a compreensão de forma, a diferenciação de forma e a abstração (inteligência fluida). Fatores sem correlação com a idade eram: o ritmo psicomotor, o conceito espacial e o fator de - aspectos globais dos desempenhos intelectuais. Várias pesquisas confirmaram esses dados.

b) Um fator negligenciado pelo modelo de declínio foi a Velocidade ou a Limitação de Tempo. A "perda de desempenho" manifestada nas primeiras pesquisas sobre a inteligência de Yerkes, Miles e Jones e Conrad se devia principalmente à limitação de tempo. Eliminando o fator tempo, o desempenho é igual ao dos jovens ou até melhor, como mostrou Lorge (1936) reestudando o material de Miles. Estes achados que se referem ao tempo de processamento de informação e de reação levaram Birren (1965) à convicção de que o "re- tardamento do comportamento é o processo primário do envelhecimento". O fator velocidade, ou melhor, diminuição da velocidade influencia muitos tipos de comportamentos como a atualização do conhecimento geral, a solução de problemas, a combinação e muitas operações de tomada de informação, de decisão, de reação e de feedback.

Vários experimentos foram feitos sobre este assunto, relatamos apenas um. Chown (1968) testou 200 homens entre 20 e 82 anos com uma bateria de testes de inteligência, de psicomotricidade e de rigidez. Concluiu: a rapidez de desempenho é o único fator que se correlaciona muito com a idade. Os elementos de velocidade influenciam os idosos na inteligência não verbal ou de execução. Os testes de reação em pessoas idosas são uma medida para a capacidade de inteligência não verbal.

A necessidade de mais tempo pode depender de vários fatores, por exemplo:

1) fatores sensoriais (tomada de informação);

2) processos fisiológicos cerebrais;

3) aumento de tempo para chegar a uma decisão;

4) reagir somente quando se alcança um grau mais alto de certeza, correr menos riscos;

5) os mais jovens, por causa de seu trabalho constante são mais acostumados e pressionados para trabalhar rapidamente.

c) Outro fator é a Aptidão Inata, que foi estuda$\mathrm{da}$ através de pesquisas longitudinais que começaram nos EUA nos anos 20 e que são muito demoradas.

Terman começou em 1923 observando escolares bem dotados e os observou até aos 50 anos. $O$ desempenho intelectual se manteve e em alguns pontos até aumentou. A conclusão final era que em pessoas com um QI inicial alto, o declínio começa muito mais tarde e com uma diminuição muito gradativa.

Owens (1953) testou 127 estudantes nascidos em 1900 com o Army Alpha em 1919, o repetiu 31 anos depois, em 1950, e constatou que tiveram um bom progresso nos subtestes de conhecimento e de vocabulário. Repetiu de 
novo a avaliação em 1961 e constatou que muitos fatores tinham ficado constantes e que, de 1950 a 1961, não houve um declínio estatisticamente significativo no desempenho intelectual. Além disso, constatou uma grande variabilidade interindividual. Uma das conclusões era a de que nessas pesquisas o desempenho intelectual tinha aumentado tanto quanto se esperava que diminuísse conforme as pesquisas transversais de Jones. Resumindo: as pesquisas longitudinais mostraram que o declínio de desempenho intelectual com a idade não é regra.(Owens,1966)

d) O Nivel de Instrução é outro fator que não foi levado em consideração nas pesquisas transversais, porém ele é de maior impacto nos grupos dos mais jovens do que nos dos mais idosos. Também sobre este ponto várias pesquisas foram realizadas; relatamos apenas uma. Birren e Morrison (1966) mostraram mudanças nos resultados do Wechsler Adult Intelligence Scale (WAIS) pesquisando com quatro grupos de idade: $25-34,35-44,45-54$, 55-65, com três tipos de nível de instrução: 1) com menos de oito anos de escola primária, 2) com oito a doze anos de escola, 3) com treze ou mais anos de escola (universidade ou outra). Os resultados eram melhores na medida que as pessoas tiveram tido mais instrução, em todas as classes de idade.

É lógico que aquele que saiu do primeiro grau em 1995 teve mais informação na escola, nos livros mais modernos, na TV e nos jornais do que aquele que saiu em 1935. Comparando grupos de 20 e de 60 anos não se deve esquecer esta evolução histórica. Mesmo quando se tem o mesmo tipo de instrução, as diferenças não devem ser consideradas como necessariamente causadas pela idade.

Comparando os níveis educacionais com os resultados nos testes de dependência/independência do campo, mostramos que há aumento de independência nos níveis educacionais mais altos (Rozestraten,1988b).

e) O Treinamento Profissional e o Tipo de Profissão é outro fator que influencia o desempenho intelectual, independentemente da idade.
Vernon (1947) já constatou que profissões com trabalho muito monótono e simples provocam. um declínio mais cedo, mas nos casos em que as funções intelectuais são exercitadas pode até haver um progresso com o tempo. Wagner (1960) comparando jovens e idosos empresários e diretores, verificou que os resultados nos mais velhos eram iguais ou melhores que nos mais moços, porém com maior variabilidadę. Welford (1966) mostrou o que chamou de "Occupational transfer effect": através da atividade profissional são treinadas áreas inteiras de aptidões, que também podem se mostrar através da solução de problemas fora da profissão.

f) $O$ Ambiente Estimulante influencia, sem dúvida, o desenvolvimento intelectual já na primeira infância. Heron et al. (1956) mostraram que a privação sensorial pode ter consequiências mais severas e mais rápidas do que a privação social. Mostraram que o trabalho monótono tem um efeito negativo sobre o desenvolvimento da inteligência. Outros estudos compararam idosos de ambientes estimulantes com indivíduos equivalentes de ambientes com pouca estimulação. Meio ano depois verificaram uma diminuição nas capacidades intelectuais desses últimos.

g) O fator Salide deve ser considerado, pois, nas pesquisas transversais compararam-se muitas vezes idosos doentes com jovens sadios e debitaram as diferenças na conta da idade avançada. Um dos mais importantes estudos foi o chamado Estudo de Bethesda de Birren e cols. (1963), onde 20 cientistas de diversas áreas pesquisaram 47 homens durante 14 dias no National Institute of Mental Health in Bethesda. A condição para participar era: não ter sintoma de doença. Através de critérios estabelecidos depois do exame médico formaram-se três grupos: Grupo I: 27 homens com excelente saúde, Grupo II: 20 homens com saúde um pouco abalada e Grupo III: o grupo padrão do WAIS de 25 a 36 anos, como comparação. A média de idade dos dois primeiros grupos era 72 anos. Os resultados médios do Grupo I mostraram resultados bem acima do 
padrão nos testes compreensão verbal, conhecimento geral, vocabulário e inteligência aritmética; nesses mesmos itens, o Grupo II alcançou o padrão. Em todos os outros testes Grupo I e Grupo II estavam abaixo do padrão, mas o Grupo I estava melhor que o Grupo II em praticamente todos os itens. Portanto, pode-se afirmar que o estado de saúde, mesmo sem doença nenhuma, afeta o desempenho intelectual.

A partir dos resultados desse e de outros estudos chegou-se à conclusão que grande parte de "mudanças comuns de velhice" têm uma relação com processos mórbidos que não aparecem necessariamente nos idosos, mas que se tornam mais prováveis na idade avançada. Envelhecimento pode significar uma afetação de saúde e da capacidade de desempenho intelectual mas não necessariamente.

h) Os Elementos Biográficos são outros fatores importantes negligenciados pelo Modelo de Declínio. Owens $(1953,1966)$ fez pesquisas longitudinais seguindo pessoas nascidas em 1900 até aos 60 anos. A conclusão de sua pesquisa é que há uma alta correlação entre a capacidade intelectual constante e sucesso no trabalho, aceitação da vida, atividade e facilidade de contatos sociais.

Tismer (1969) mostrou uma correlação positiva entre interesses, referências e sucessos na vida profissional, manutenção de contatos sociais e resultados melhores nos testes de inteligência. Também Lehr (1967) e Schreiner (1969) mostraram uma correlação positiva em relação ao futuro e uma capacidade de desempenho intelectual mais alta $(\mathrm{QI}>115)$, contra uma atitude negativista e um desempenho intelectual, mais baixo $(\mathrm{QI}<100)$.

i) O fator Motivação influencia o desempenho intelectual apesar de ser bastante discutido "como". Alguns acham que os idosos são menos motivados para fazer 0 teste, pois não é para eles uma situação de competição e, por isso, são menos orientados para o desempenho. Existem várias diferenças no desempenho que podem ser vistas como diferenças de motivação. No entanto, as pesquisas de
Eisdorfer (1969) mostram que nos idosos há freqüentemente uma alta motivação e ụm grande engajamento. Eles querem mostrar que são bons ainda. Por isso a situação do teste pode gerar estresse, tensão e medo que bloqueiam as respostas certas que poderiam ser dadas.

Oberleder (1964) supõe que os escores nos idosos que fazem pensar em declínio e senilidade indicam mais uma reação de fuga $e$ mecanismos de defesa do que um declínio intelectual. Principalmente o medo os afeta. Para julgar bem os resultados, deve-se ter uma boa visão da situação total. Em outras palavras: até que ponto os elementos emocionais fazem decrescer o rendimento nos testes? A questão geral é: mede-se nos testes realmente o desempenho que a pessoa é capaz de dar? Pode bem ser que os resultados somente digam alguma coisa sobre o comportamento de estresse no idoso.

Bischof (1969) anota aqui que "De alguma maneira não parece que os aplicadores dos testes de inteligência usaram muita inteligência para testar a inteligência dos adultos". Resumindo podemos concluir que a variável "idade" é apenas um dos determinantes das capacidades de desempenho intelectual na idade avançada. Rudinger (1975) calculou, por uma análise de variância, sobre os dados do estudo de Bonn (Hamburg-Wechsler Teste de Inteligência, Riegel) a participação dos diversos fatores, expressando-os em porcentagens nos diversos subtestes do WAIS. Por fim, formulou a seguinte conclusão: "Indicação de idade é no máximo uma abreviação de um grande número de eventos que aconteceram $\mathrm{e}$ que de sua parte são responsáveis pelas modificações do comportamento..... Ou apenas um número para indicar que não sabemos tudo que contribuiu para o comportamento, assim como se manifesta no dado momento".

Baseando-nos sobre os dados mencionados, podemos rejeitar como um mito que eventuais declínios no desempenho intelectual são somente devido ao fator idade: vários outros fatores podem provocar esse resultado. 
Um fator importante geral para manter um desempenho intelectual bom ou razoável nos parece o interesse em aprender novas coisas e se manter a par do que passa no seu ambiente, no país e no mundo, bem como manter alguma atividade física.

\section{A Tomada de Decisão}

Muitas vezes a tomada de decisão é confundida com o tempo de reação ou se engloba, no tempo de decisão, todo o tempo necessário para a tomada e o processamento de informações ou é identificada com o tempo de julgamento do que é bom ou melhor a fazer. De modo geral, tem-se a convicção que o idoso demora mais em decidir-se, tem mais medo de correr riscos ou de ser enganado, pois tem mais consciência de sua fragilidade. Ele conhece suas restrições e volta literalmente para trás nos seus processos cognitivos, ponderando várias vezes os valores $\mathrm{e}$ as motivações. Não é a própria decisão que demora, mas a falta de decisão, a dúvida se a decisão proposta está bem fundamentada ou não. Algumas decisões recentes que não deram certo podem agravar mais a situação.

\section{A Reação ao estímulo: a Resposta ou o Comporta- mento}

Os hábitos específicos do trabalho de um profissional que seguramente suportam $90 \%$ de sua atividade profissional, são aprendidos através de uma longa aprendizagem que permitiu eliminar ações supérfluas, fixar movimentos e ações mais adaptadas e reagir mais rapidamente em certas eventualidades. O mesmo vale também para os comportamentos sociais.

No entanto, podem surgir dificuldades quando se trata de uma aprendizagem com novos aparethos como computadores e controles remotos, em que os jovens se mostram mais hábeis. Porém, grande parte desta dificuldade de se adaptar a estes novos inventos nos parece correr por conta de uma tecnofobia. Há uma quantidade razoável de idosos que conseguiram se adaptar e até se tornaram internautas. Pode ser que esta adaptação nos idosos vá mais lenta que nos jovens, mas normalmente eles têm tempo; falta às vezes a coragem e, às vezes, aceitar aprender as coisas novas com os netos!
Por outro lado vemos que há tentativas, como na Suécia, para aproveitar melhor a experiência dos trabalhadores mais idosos e sua capacidade intelectual junto com o acúmulo de eventos pelos quais passaram nas suas vidas, contratando-os como orientadores de treinamento de novos trabalhadores.

\section{O Feedback}

Para poder falar mais concretamente sobre esta fase haveria necessidade de observações e estudos científicos dos acidentes em pessoas idosas. Sem dúvida boa porcentagem de acidentes domésticos e acidentes de trabalho acontecem com as pessoas idosas. Entre os últimos, temos os acidentes de trânsito. Das vítimas fatais no trânsito, $25 \%$ são idosos. A probabilidade é grande de não ter ocorrido um eficiente "feedback" da ação que estavam executando. Não calcularam bem quais as conseqüências de suas ações, ou a atenção começou a vacilar ou se pensou que os mais jovens deveriam ter respeito e cuidado com os mais idosos. Às vezes pode haver uma nãoaceitação de seu estado físico deteriorado, julga-se que ainda vai dar certo. Os idosos às vezes são mais "cabeçudos"; por fim, a previsão não dá certo e acontece o acidente. (Rozestraten,1997)

\section{Considerações Finais}

Com o constante aumento de pessoas idosas na sociedade, torna-se necessário o aumento também dos grupos de geriatras nas universidades. Ainda são relativamente poucos os grupos de pesquisadores na gerontologia, tanto na parte de psicologia como na pedagogia, antropologia e na sociologia.

Pretendemos através deste artigo contribuir para a refutação de mitos prejudiciais sobre a capacidade intelectual dos idosos. Primeiro, o mito de que a inteligência seria uma capacidade única em vez de um conjunto de diversas capacidades intelectuais que se combinam de múltiplas formas. Segundo, o mito de que a inteligência como totalidade única se deteriora durante a velhice, enquanto se verificou posteriormente que apenas algumas capacidades agrupadas, como inteligência fluida, são afetadas; enquanto outras caracterizadas como inteligência cristalizada ficam constantes ou até melhoram. Terceiro: o mito de que a idade avançada seria 
o único fator que influenciaria o desenvolvimento ou deterioração das capacidades intelectuais. No entanto, verificou-se que, no mínimo, há mais nove fatores influentes: declínio de fator $\mathrm{G}$, rapidez, aptidão inata, nível educacional, treinamento, ambiente estimulante, saúde, sucesso na vida e motivação.

Temos ainda que acrescentar que o ciclo de processos psíquicos é continuamente influenciado pelos traços de personalidade, pelas emoções, pelas atitudes e pelos problemas vivenciais dos idosos. Às vezes, a capacidade intelectual está presente, mas as dificuldades vivenciadas tornam quase impossível seu uso adequado.

\section{Referências Bibliográficas}

Birren, J.E. (1965) Age changes in speed of behavior: its central nature and physiologicasl correlates. In Welford \& Birren (Eds) Behavior, aging and the nervous system. (191-216) Thomas: Springfield (III).

Birren, J.E., Butler, R.N., Greenhouse, S.W., Solokoff, L. \& Yarrow, M.R. (1963). Human aging: a biological and behavioral study. Nat. Inst. of mental health. Bethesda: Maryland

Birren, J.E., Cunningham, W. \& Yamamoto, K. (1983). Psychology of adult development and aging. Annual Review of Psychology,34: 543575

Birren, J.E. \& Morisson, D.F. (1966). Analysis of the WAIS subtests in relation to age and education.Journal. of Gerontology, 18, 363-369.

Bischof, L.B. (1969). Adult Psychology.New York: Rarper and Row

Bromsley, D.B. (1969). Psicologia do envelhecimento humano. Lisboa: Ulissea.

Bunch, C.C. (1931). Further observations on age variation in auditory acuity. Archives of Otolaryngology, 13: 170-180.

Chown, S. (1968). Rigiditätsarten und Lebenșalter. In Thomae e Lehr (eds) Altern-Probleme und Tatsachen (203-206) Frankfurt: Verlag

Coleman, D. (1995). Inteligência Emociona. Rio de Janeiro: Ed. Objetiva
Dejours, C. (1987). A Loucura do Trabalho, São Paulo: Oboré Ed.

Dennis, W. (1966). Creative productivity between the ages of 20 and 80 years., Journal of Gerontology, 21, 1-8.

Eisdorfer, C. (1969). New demensions and tentative theory, Symposium on Learning and Memory. Gerontologist, 7: 14-18.

Foster, J.C. \& Taylor, G.A. (1920). The applicability of mental tests to persons over fifty years of age. Journal of Applied Psycholog,4:39-58.

Gaiarsa, J.A. (1986). Como enfrentar a velhice. São Paulo: Ed.Unicamp Icone

Helander, J. (1975). Age, learning capacity, and the need of acquiring knowledge throughout the lifespan Proc. X Intern Gerontol.,I, Jerusalem, 346-348.

Helander, J. ( 1967). On age and mental test behavior, Acta Psychol. Gothoburgensia, Göteburg.

Heron, W., Doane, B.K. \& Scott, T.M. (1956). Visual disturbance after prolonged perceptual isolation, Canad. J.Psychology, 10,15-18.

Horn, J.L. \& Cattell, R.B. (1966). Age differences in primary mental ability factors. Journal of Gerontology, 21, 210-220.

Jones, H.E. \& Conrad, H.S. (1933). The growth and decline of intelligence: study of a homogeneous group between the ages ten and sixty. Genet. Psychol. Monogr. 13: 223-298.

Lehman, H.C. (1964). The relationship between chronological age and high level research output in physics and chemistry. Journal of Gerontology, 19: 157-164.

Lehman, H.C. (1965). The production of masterworks prior the age 30. Gerontologist, 5, 24-29.

Lehman, H.C. (1966). The most creative years of engineers and other technologists. Jorunal Genet. Psychology, 108: 263-277.

Lehr, U. (1980). Psychologie van de ouderdom. Trad. Jos Tielens e Kees van Eekelen, orig. "Psychologie des Alterns"; Van Loghum: Van Loghum. 


\section{Reinier Johannes Antonius Rozestraten}

Lehr, U. (1967). Attitudes toward the future. Human Development, 230-238.

Lorge, I. (1936). The influence of the test upon the nature of mental decline as a function of age. Journal Educ. Psychol., 27: 100-110.

Lowe, F.E. \& Mccormick, (1955). Some survey sampling biases. Publ. Opin. Quart. 19, 303-315.

Miles, C.C. \& Miles, W.R. (1932). The correlation of intelligence scores and chronological age from early to late maturity. American Journal Psychol. 44: 44-78.

Owens, W.A. (1953). Age and mental abilities: a longitudinal study. Genet. Psychol. Monogr., 48:354.

Owens, W.A. (1966). Age and mental abilities: a second follow-up. Journal of Educational Psychology, 57: 311-325.

Oberleder, M. (1964). Effects of psychosecial factors in test results on the aging. Psychol. Report, 14: 383-387.

Riegel, R.M. (1960). Faktorenanalysen des HamburgWechsler-Intelligenztests für Erwachsene für de Alterstufen 20-34,35-49,50-64, und 65 Jahre und alter. Diagnostica, 6: 41-66.

Robertson, G. \& Yudini, J. ( 1944). Effect of age upon dark adaptation. Journal of Psychology, 103: $1-8$

Rozestraten, R.J.A. (1997). Manual de Trânsito da Terceira Idade. Campo Grande, DETRAN-MS

Rozestraten, R.J.A. (1988a). O idoso, suas capacidades psíquicas e o trabalho. Ciência e Cultu$r a, 40(7)$ : 673-679.

Rozestraten, R.J.A. (1988b). Educational Levels and field-dependent/field-independent perceptual style. Bulletin of Psychonomic Society, 26(2), 212-213.

Rudinger, G. (1975). Die Bedeutung von Längsschnitt und Querschnitt-untersuchungen für die Messung intra-und interindividueller Differenzen. In U. Lehr \& F.E.Weinert (red.): Entwicklung und Persönlichkeit, Stuttgart: Kohlhammer

Schreiner, M. (1969). Zur zukunftbezogenen Zeitperspektive bei alten Menschen.Bonn: Phil,
Diss Shinar, D., Mcdowell, E., Rackoff, N. \& Rockwell, T. (1978). Field dependend and driver visual search behavior. Human Factors, 20: 553339.

Tismer, K.G. (1969). Untersuchungen zur Lebensthematik älterer Menschen. Phill. Diss. Bonn

Vernon,P.E. (1947) The variation of intelligence with occupation, age and locality. Brit. J. Psychol. 1: 52-63.

Verville, E. \& Cameron, N. (1946). citado em Shock (1951) Journal of Genetic Psychology, 68: 149157.

Wagner, E.E. (1960). Differences between old and young executives on objective psychological test variables. Journal of Gerontology, 15: 296-299.

Wechsler, D. (1955). Manual for the Wechsler adult intelligence scale. Psychol. Corpor. New York.

Welford, A.T. (1966). Industrial work suitable for older people: some British studies. Springfield: Thomas

Wright, R. (1981). Aging, divided attention and processing capacity. Journal of Gerontology, 36: 605-614. 